\title{
Pobreza multidimensional e seus aspectos subjetivos em contextos rurais e urbanos nordestinos ${ }^{1}$
}

Verônica Morais Ximenes. Universidade Federal do Ceará. James Ferreira Moura Júnior. Universidade da Integração Internacional da Lusofonia Afro-Brasileira. Janaína Miranda Cruz. Centro de Referência da Assistência Social do Município do Euzébio (Ceará). Lorena Brito da Silva. Faculdade Luciano Feijão. Jorge Castellá Sarriera. Universidade Federal do Rio Grande do Sul.

\section{Resumo}

Objetiva-se analisar a pobreza multidimensional e seus aspectos subjetivos em contextos rural e urbano em um Estado do Brasil. Os aspectos subjetivos da pobreza estão relacionados a uma autopercepção vinculada à privação financeira e à responsabilização individual. A amostra total constou de 417 participantes. Foi desenvolvido um Índice de Mensuração de Pobreza Multidimensional a partir das privações nas dimensões habitação, escolaridade, trabalho/renda, saúde e aspectos subjetivos da pobreza. Foram realizados testes de Análise de Regressão Múltipla e Análise Multivariada de Variância. Identificou-se que as privações nas dimensões escolaridade e habitação são mais intensas na zona rural. Já a dimensão subjetiva da pobreza é mais forte no contexto urbano. Em ambos os contextos, dimensão privação de trabalho/renda tem predição positiva com os aspectos subjetivos da pobreza. No contexto urbano, as dimensões saúde e habitação também são preditoras positivas da dimensão subjetiva da pobreza, enquanto a dimensão educação tem uma correlação negativa.

Palavras-chave: pobreza; contexto rural; contexto urbano.

\begin{abstract}
Multidimensional poverty and its subjective aspects in rural and urban contexts in Northeast Brazil. The objective is to analyze the multidimensional poverty and its subjective aspects in rural and urban contexts in a State of Brazil. The total sample consisted of 417 participants. It was set up the Measurement Index of the Multidimensional Poverty from deprivation in housing, education, work/income, health dimensions and subjective aspects of poverty. Multiple Regression Analysis and Multivariate Analysis of Variance were performed. It was found that the deprivations in the education and housing dimensions are more intense in the countryside. The subjective dimension of poverty is stronger in the urban context. In both contexts, deprivation of work/income dimension has positive prediction with the subjective aspects of poverty. In the urban context, health and housing dimensions are also positive predictors of subjective dimension of poverty, while the education is has a negative correlation.
\end{abstract}

Keywords: poverty; rural context; urban context.

\section{Resumen}

Pobreza Multidimensional y sus aspectos subjetivos en contextos rurales y urbanos de Nordeste. El objetivo es analizar la pobreza multidimensional y sus aspectos subjetivos en contextos rurales y urbanos en un Estado del Brasil. El total de la muestra consistió en 417 participantes. Se ha creado un índice de medición de pobreza multidimensional por medio de las privaciones en las dimensiones de la vivienda, la educación, el trabajo/ingreso, la salud y los aspectos subjetivos de la pobreza. Las pruebas se realizaron en el Análisis de Regresión Múltiple y Análisis Multivariado de Varianza. Se constató que las variaciones en las dimensiones de la educación y la vivienda son más intensas en el campo. La dimensión subjetiva de la pobreza es más fuerte en el contexto urbano. En ambos contextos, la privación de la dimensión trabajo/ingreso cuenta con la predicción positiva con los aspectos subjetivos de la pobreza. En el contexto urbano, las dimensiones salud y vivienda son también predictores positivos de la dimensión subjetiva de la pobreza, mientras que la educación tiene una correlación negativa.

Palabras clave: pobreza; contexto rural; contexto urbano. 
Uma das manifestações contemporâneas mais presentes e importantes na questão social no Brasil é a pobreza. O relatório da Organização das Nações Unidas para a Alimentação e a Agricultura (FAO, 2014) divulgou que o índice de pobreza reduziu no Brasil de $24,68 \%$, em 2002 para $8,5 \%$, em 2012, e que a extrema pobreza caiu de $9,79 \%$ para $3,56 \%$ em igual período, sendo, de acordo com o Programa das Nações Unidas para o Desenvolvimento (PNUD, 2010), o valor diário correspondente para o indivíduo se manter na linha da extrema pobreza o equivalente a U\$\$1,25 dólares ${ }^{2}$. No ano de 2013, o Instituto de Pesquisa e Estratégia Econômica do Ceará (IPECE, 2014a) destaca que o percentual da proporção de extremamente pobres ${ }^{3}$ do nordeste brasileiro na zona rural é de $14,87 \%$ e na zona urbana de $6,28 \%$, deflagrando uma significativa redução da situação de extrema pobreza nessa região no espaço de três anos.

Esses resultados apresentados baseiam-se na visão monetária de pobreza e, portanto, unidimensional, envolta por propostas de intevenção cerceadas por uma visão neoliberal. Esta perspectiva, de acordo com Accorssi, Scarparo e Guareschi (2012), contribui para um processo de naturalização do fenômeno da pobreza. Tais formas de avaliação reduzem o conceito de pobreza à insuficiência de renda (Cattani \& Ferrarini, 2010) e à necessidade biológico-alimentar de subsistência. Apesar dos avanços da redução da extrema pobreza, os índices ainda demonstram a necessidade de dar continuidade às formas de enfretamento a essa questão social. Além disso, no Brasil, considera-se que não há um consenso quanto à definição de linha de pobreza, ficando a cargo das instituições de pesquisa ou secretarias de governo os critérios e metodologias utilizados para sua mensuração. Essa diversidade pode direcionar para diferentes números estatísticos.

Na perspectiva monetária, a pobreza é mensurada pelo valor da renda que, por sua vez, se torna o critério delimitador para o estabelecimento de um limiar entre pobres e não pobres. Loureiro, Suliano e Oliveira (2010) destacam dentre os diferentes parâmetros para a definição das linhas de pobreza: a fração do salário mínimo, o consumo mínimo para a sobrevivência, a definição de US\$1,25 dólares por dia e a variável da renda familiar. Dessa maneira, baseando-se somente na renda, há diferentes impactos da realidade de pobreza nas zonas rurais e urbanas.

É importante salientar que o urbano historicamente é com densidade demográfica, econômica e étnica (Bezerra, 2009). Verifica-se uma maior oferta de serviços públicos desenvolvidos pelas políticas públicas e maior dinamismo econômico e laboral (Pinto, Borges, Novo, \& Pires, 2014). No entanto, também, é perceptível uma excessiva desigualdade social. Além disso, há alta concentração populacional e maior identificação de índices de violência, de criminalidade e de abuso de drogas. Atualmente, a urbanidade é entendida como processo socioeconômico e cultural marcada por uma relação com a temporalidade bastante específica.

Já o contexto rural é comumente associado às características econômicas - campo, agrícola, não agrícola. De acordo com Albuquerque (2002), essa é uma problematização descontextualizada, visto que o rural não é um tipo de produção e sim um modo de vida, que possui uma relação específica com o tempo, com a terra e com o outro (vizinhança). Dentre as principais características, destaca-se uma concentração populacional menor e uma pluriatividade econômica, o que acaba por aproximar as pessoas em estratégias colaborativas de viver: comercialização, transporte e rituais de cuidado e espiritualidade compartilhados. É importante salientar que o contexto rural é marcado pela pobreza de caráter estrutural, ou seja, com o perfil mais crônico que nas áreas urbanas (Pinto et al., 2014).

Igualmente, o contexto rural não pode ser compreendido contendo uma menor intensidade de problemas sociais. Deve-se entendê-lo como uma complexidade das relações de poder, uma invisibilidade diante de uma aparente igualdade social e uma dificuldade de cobertura das políticas públicas, apesar de se observar atualmente avanços nas políticas de cunho econômico, produtivo e estrutural. As ruralidades e urbanidades se encontram de forma complexa nos territórios em diferentes municípios. O urbano contém traços do rural em si (Albuquerque, 2002), basta pensarmos nos processos de construção dos primeiros bairros das cidades e na migração que aconteceu para capital por conta das grandes secas que afetaram o Estado nos séculos XIX e XX.

Entende-se que é imprescindível pensar sobre como os modos de vida de pessoas em situação de pobreza são construídos em meio às singularidades dos contextos urbanos e rurais. Além disso, é necessário desenvolver estudos comparativos nas áreas com enfoques que vão para além da prerrogativa unidimensional da pobreza. Assim, a utilização da perspectiva multidimensional deste fenômeno pode trazer evidências mais detalhadas 
sobre sua diferença nesses contextos. Moura Jr., Cidade, Ximenes e Sarriera (2014), enfatizam a necessidade de abordar a pobreza em uma perspectiva multidimensional baseada na Abordagem das Capacitações (Sen, 2000). Compreende-se, portanto, neste estudo, a pobreza enquanto privação das capacitações básicas do ser humano constituída por aspectos sociais, culturais, políticos, materiais, monetários, simbólicos e ideológicos. As capacitações têm que ser entendidas como conjuntos de funcionamentos, onde a pobreza se caracterizaria como a não satisfação dos funcionamentos (Picolotto, 2006). Assim, esses funcionamentos são abordados como os diferentes estados de ser e de fazer que o indivíduo pode realizar.

Quanto a dados estatísticos e sobre o parâmetro das duas principais linhas de análise da pobreza (unidimensional e multidimensional), o PNUD (2014) faz uma comparação e aponta que no Brasil 3,1\% da população é pobre multidimensionalmente, enquanto um adicional de 7,4\% da população está próximo à pobreza multidimensional. Além disso, vale ressaltar que a Abordagem Multidimensional da Pobreza (Sen, 2000) considera geralmente as dimensões de saúde, educação e padrão de vida, porém não contempla de modo aprofundado a dimensão subjetiva da vida em condições de pobreza.

Da mesma forma, a teorização utilitarista e monetária deste fenômeno deixa de lado a vivência em condições de pobreza e suas implicações concretas e subjetivas no desenvolvimento do psiquismo e nos modos de viver. É importante salientar que há as linhas de pobreza subjetiva que são as opiniões dos indivíduos sobre o nível de renda necessária para a sobrevivência (Spicker, Leguizamón, \& Gordon, 2009). No entanto, este estudo entende os aspectos subjetivos da pobreza não como um valor monetário, mas como a autopercepção do indivíduo como pobre. Identifica-se que esta percepção pode estar vinculada a identificação, a perspectiva de escolhas que, segundo Distante (2013), estão relacionadas à estrutura cognitiva do indivíduo, ao contexto cultural e as ambições pessoais.

Seguindo essa linha de raciocínio, compreendese o aspecto subjetivo da pobreza como um constructo simbólico do sujeito imerso em uma realidade social que o está constituindo, sendo, portanto, influenciado por uma cultura que interfere no modo pelo qual se conceitua a pobreza (Accorssi, 2011). O perigo está naquilo que está impregnado na atual conjuntura política e econômica baseado em uma cultura neoliberal que preza pela valoração do acúmulo de riquezas e assim se corre o risco de favorecer a uma autopercepção da pobreza baseada somente na renda, cujo pobre seria aquele que não tem rendimentos necessários para suprir suas necessidades.

Também, pode-se perceber que os aspectos subjetivos da pobreza aproximam-se do conceito de subjetividade da pobreza e do bem estar de acordo com Wang, Shang e Xu (2011). Essa subjetividade seria a avaliação das condições de vida gerais do indivíduo incluindo sua renda. Assim, uma autoavaliação negativa das condições de vida seria categorizada como autopercepção vinculada à pobreza. E como essa pobreza é constituída de maneira estigmatizada, há igualmente questões dos aspectos subjetivos da pobreza que podem estar relacionadas a sentimentos de autodepreciamento pelo indivíduo ao identificar-se como estando em situação de pobreza (Zavaleta, 2007). De acordo com Moura Jr., Sarriera e Ximenes (2014), há um pensamento social que restringe a pobreza à renda principalmente em no território brasileiro marcado por um histórico de alta desigualdade social, culpabilizando somente o indivíduo pela sua situação. Dessa maneira, pode-se desenvolver uma estrutura psíquica na pessoa em situação de pobreza restrita parâmetros monetários e individualizantes de uma autopercepção de pobre.

Esse prisma de compreensão da realidade é importante, porque pode influenciar na forma como o indivíduo posiciona-se na sociedade independente de critérios objetivos e monetários. De acordo com Copestake e Camfield (2010), a avaliação que o indivíduo desenvolve relacionada ao seu contexto vivido está estritamente relacionada com sua posição social. Os autores informam que pode haver mecanismo de adaptação dessa avaliação quando há um histórico de privação de satisfação do indivíduo, como ocorre nos contextos de pobreza. Assim, os aspectos subjetivos da pobreza podem estar relacionados a uma autopercepção estigmatizada e adaptada àquela realidade.

Assim, tem-se como objetivo, neste estudo, analisar a pobreza multidimensional e seus aspectos subjetivos em contextos rural e urbano de um Estado brasileiro. É possível perceber uma escassez de trabalhos que lancem tal recorte para o estudo do fenômeno, sendo ainda mais desafiador e urgente a realização de um estudo que ultrapasse a visibilidade de porcentagens e que possa problematizar os impactos das circunstancias com a satisfação e autopercepção dos modos de viver. 


\section{Método}

Esse estudo faz parte um uma pesquisa sobre os impactos da pobreza em comunidades rural e urbana de um Estado brasileiro. No caso especifico deste trabalho, teve como foco o delineamento quantitativo e a análise da pobreza multidimensional e seus aspectos subjetivos. Essa pesquisa foi aprovada pelo Comitê de Ética em Pesquisa de uma instituição de ensino superior.

O cenário desse estudo engloba duas comunidades. A comunidade urbana, localizada na periferia de uma grande capital brasileira, tem aproximadamente 220.000 habitantes. Além de ser considerada uma das regiões mais populosas dessa capital, é classificada com o maior número de contingente de pessoas em situação de extrema pobreza com 20.459 habitantes nesse contexto (IPECE, 2012).

A comunidade rural pesquisada localiza-se aproximadamente a $118 \mathrm{~km}$ da capital do estado e possui em torno de 170 famílias, totalizando um pouco mais de mil pessoas. A forma de subsistência local provém da agricultura familiar, benefícios sociais, funcionalismo público e aposentadorias. Vale ressaltar que nesta comunidade $37,84 \%$ da população rural vivem no contexto de extrema pobreza (IPECE, 2014b).

\section{Participantes}

A amostra é composta por 417 pessoas, sendo 209 pessoas da zona urbana e 206 pessoas da zona rural. A média de idade é de aproximadamente 42 anos ( $D P=$ $18,92)$ nos moradores da zona rural e $34,61(D P=14,13)$ anos de residentes na comunidade urbana. Alguns dados sociodemográficos caracterizam a amostra, dentre eles a renda dos participantes, pelo qual 104 informam ter uma renda inferior à $\mathrm{R} \$ 85,00$ (24,9\%), sendo classificados na faixa de extrema pobreza, 225 possuem uma renda pessoal superior à $R \$ 85,00$ e inferior a um salário mínimo $(54,6 \%)$ e 83 afirmam obter uma renda superior a $R \$ 678,00^{4}(19,9 \%)$.

\section{Instrumentos}

Foi adaptado e construído um Instrumento de Mensuração da Pobreza Multidimensional com 24 itens representando indicadores que estão divididos em cinco grandes dimensões baseadas no Índice Multidimensional de Carências de Porto Alegre. Este índice foi elaborado por meio de consulta popular sobre os principais fatores que caracterizariam uma situação de pobreza, contando com a participação de 8.000 pessoas da capital gaúcha
(Avila, Bagolin, \& Comim, 2012). É importante salientar que outros trabalhos foram utilizados para construir o instrumento do presente trabalho, como o Índice de Pobreza Multidimensional do PNUD (2010) e pesquisas sobre pobreza multidimensional aplicada na África do Sul (Qizilbash \& Clark, 2005), na Itália (Chiappero-Martinetti, 2000) e na Bélgica (Lelli, 2001).

Com isso, as quatro dimensões evidenciadas foram: habitação, trabalho e renda, saúde e educação. A quinta dimensão foi elencada a partir das contribuições de Samman (2007) sobre a importância de aspectos subjetivos na compreensão multidimensional da pobreza. A dimensão educação foi constituída pelos indicadores relacionados à escolaridade e à existência de adulto na família com mais de nove anos de estudo. A dimensão habitação vinculava-se ao tipo de propriedade da residência, de piso da casa, de combustível usado, de sanitário, existência de água encanada, de eletricidade e de saneamento básico.

Já a dimensão trabalho e renda continha itens vinculados à realização de trabalho remunerado, à renda pessoal, à renda familiar, ao comportamento de vender algo para poder comer e ao comportamento de pedir dinheiro para poder comer. Na dimensão saúde, constam os indicadores relacionados à obtenção de atendimento médico, à impossibilidade de atendimento médico por falta de dinheiro, à quantidade de refeições diárias, à existência de alguma pessoa com desnutrição e de mortalidade infantil.

A dimensão aspectos subjetivos da pobreza possui os seguintes indicadores relacionados à autopercepção de pobreza, à insatisfação com a renda e ao sentimento de vergonha por ser pobre. É importante salientar que foi criado um índice para mensurar a dimensão subjetiva da pobreza, sendo, como apresentada anteriormente, vinculada a uma autopercepção da pobreza ao reconhecimento da pobreza como uma identificação estigmatizada advindo do sentimento de vergonha e por fim, uma avaliação que pode ser mais adaptada ou questionadora da realidade provinda pela satisfação com a renda.

\section{Coleta e Análise de Dados}

A aplicação do questionário foi feita de maneira individual, onde cada membro da equipe de trabalho procedia com a leitura do instrumento com cada participante da pesquisa. Os mesmos foram aplicados a partir de visitas domiciliares facilitadas pelas parcerias estabelecidas nas comunidades citadas, com políticas públicas e projetos sociais. 
Para mensurar indicadores relacionados à pobreza multidimensional de forma complexa foi utilizada a metodologia dos conjuntos fuzzy que aponta diferentes graus de realização de cada indicador (Chiappero-Martinetti, 2000). Dessa maneira, os itens contidos em cada dimensão receberam valores entre 0 e 1. Este último representaria o maior grau de pobreza multidimensional, e 0 significaria a inexistência de pobreza multidimensional. Então, tanto em cada variável como em cada dimensão, quanto mais os valores das respostas estiverem próximos a 1 serão considerados mais privados, ou seja, mais pobres, e quanto mais os valores estiverem próximos a 0 serão considerados menos privados, ou seja, menos pobres multidimensionais. Com isso, é possível avaliar um conjunto de indicadores, como também de obter uma avaliação geral do grau de privação de uma pessoa ou de um agrupamento a partir de cada dimensão de funcionamentos (Lelli, 2001). A partir de Picolotto (2006) foi desenvolvida uma média de cada dimensão como forma de ponderar os índices destas.

Foram relacionadas análises descritivas com frequências e médias das variáveis trabalhadas. Em seguida, foi realizado teste $t$ para amostras independentes, comparando a média total do Índice de Pobreza Multidimensional e a dimensão dos aspectos subjetivos da pobreza nos contextos urbanos e rurais. Foi executada também uma Análise Multivariada de Variância (MANOVA) com as dimensões da pobreza multidimensional funcionando como variáveis dependentes. Assim, foram utilizadas as dimensões: educação, trabalho e renda, saúde, habitação e aspectos subjetivos da pobreza. As áreas urbana e rural foram utilizadas como grupos para identificação das diferenças entre as médias das dimensões da pobreza, utilizando o contraste polinomial. Em seguida, foi realizada uma Análise de Regressão Múltipla por meio do procedimento stepwise, utilizando o índice de significância de 0,05 (Bisquerra, Sarriera, \&Martínez, 2004). A dimensão subjetiva da pobreza é variável dependente e as dimensões escolaridade e trabalho, renda, saúde e habitação são as variáveis independentes. A ARM foi feita em uma perspectiva comparativa entre os indivíduos residentes na zona rural e na zona urbana.

\section{Resultados}

Primeiramente, identifica-se que as médias totais do Índice de Mensuração da Pobreza Multidimensional do contexto rural $(M=, 28, D P=, 10)$ e do contexto urbano $(M=.25, D P=, 11)$ diferem significativamente $(t(409,44)=-2,69, p=, 007)$. Na perspectiva de comparar as médias das diferentes dimensões da pobreza multidimensional, foi realizada uma MANOVA entre os moradores que viviam em áreas rurais e urbanas. Identifica-se que as interações entre as dimensões educação, trabalho e renda, saúde e habitação são significativas, evidenciando que há diferença de uma forma geral e multivariada relacionada à pobreza nos moradores das duas zonas $(F(2,412)=20,59, p<, 001$, Wilks' Lambda $=$,813). Em seguida, com a realização de Análises de Variância (ANOVA) para verificar as diferenças em cada dimensão da pobreza multidimensional entre os moradores das duas zonas, foram observadas diferenças significativas nas dimensões educação, habitação e aspectos subjetivos. Não foram evidenciadas diferenças significativas univariadas entre as dimensões saúde $(F(1$, $417)=, 058, p=.809)$ e trabalho e renda $(F(1,417)=, 093$, $p=, 760)$, como aponta a Figura 1.

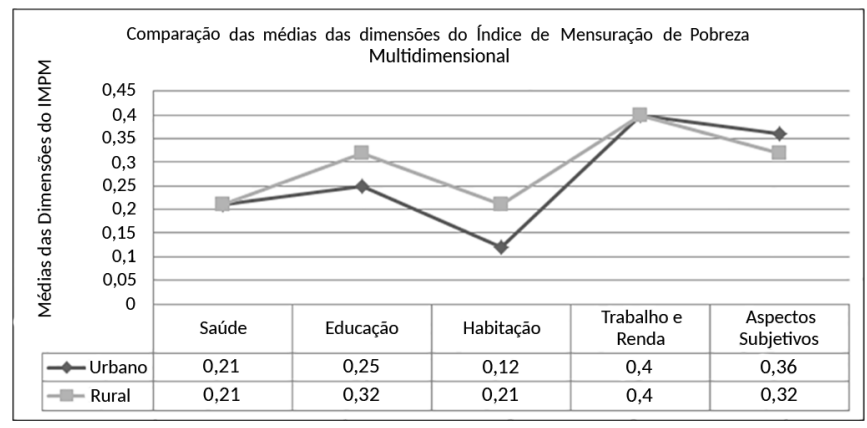

Figura 1. Gráfico Comparativo das Dimensões do Índice de Pobreza Multidimensional a Partir do Contexto Rural e Urbano.

Dessa maneira, ainda no âmbito comparativo das dimensões que foram significativas, observa-se que na dimensão educação $\left(F_{(1,417)}=6.50, p=0,011\right)$ os moradores da zona rural $(M=0,32, S D=0,29)$ eram mais pobres multidimensionais que os residentes na zona urbana $(M=0,25, S D=0,28)$. Na dimensão habitação $(F(1,417)=70,50, p<0,001)$, novamente os moradores da zona rural $(M=0,21, S D=0,12)$ são mais pobres multidimensionais que aqueles que vivem na zona urbana $(M=0,12, S D=0,11)$. Na dimensão aspectos subjetivos $\left(F_{(1,417)}=2,26, p=0,025\right)$, as pessoas residentes da zona urbana $(M=0,36, S D=0,19)$ são mais pobres subjetivamente que aqueles que vivem na zona rural ( $M$ $=0,32, S D=0,13$ ).

Em seguida, foram realizadas duas ARM com os indivíduos que residiam em áreas urbanas e outra análise 
com moradores de zonas rurais. Nessas duas ARMs, a variável dependente foi a dimensão dos aspectos subjetivos da pobreza multidimensional. As variáveis independentes foram as dimensões educação, habitação, trabalho e renda e saúde, como observado na tabela 1.

Na zona urbana, o modelo preditivo da dimensão dos aspectos subjetivos da pobreza com o nível de significância adequado foi composto de três variáveis $\left(R=0,516, F_{(4,209)}=37,27, p<0,001\right)$, tendo uma variância explicada de $26,6 \%$. A variável que tem uma maior predição dos aspectos subjetivos da pobreza é a dimensão saúde $(\beta=0,265, p<0,001)$, seguida da dimensão habitação $(\beta=0,233, p=0,001)$ e educação ( $\beta$ $=-0,232, p<0,001)$. Já, na zona rural, o modelo preditivo significativo dos aspectos subjetivos da pobreza foi constituído com somente uma variável $\left(R=0,232, F_{(1,206)}=\right.$ $11,68, p=0,001)$, tendo uma variância explicada de $5,9 \%$. A única variável que é preditora dos aspectos subjetivo da pobreza é a dimensão renda $(\beta=-, 232, p=0,001)$.

\section{Discussão}

Evidencia-se que a situação de pobreza multidimensional no contexto urbano e rural é diferente tanto em um patamar geral, como também quando relacionado a dimensões específicas. 0 ambiente rural é identificado como o mais privado multidimensionalmente. Esse resultado é compartilhado na identificação do contexto rural brasileiro como portando quase metade da população pobre $47 \%$ no Brasil ("Brasil é o segundo", 2012).

As diferenças significativas entre os contextos estão relacionadas à educação, à habitação e aos aspectos subjetivos da pobreza. Na educação, de acordo com Werneck e Leal (2011), a taxa de analfabetismo da população acima de 15 anos é aproximadamente 15\% maior nas áreas rurais do que nas comunidades pobres das cidades. Assim, o fato de a amostra de pessoas da área rural portar uma média de idade mais avançada pode trazer um dado importante para entender esses resultados, porque esse público geralmente não foi alvo de políticas educacionais desenvolvidas nos últimos anos. De acordo com a Pesquisa Nacional de Amostra por Domicílio (PNAD) do ano de 2013 (Instituto Brasileiro de Geografia e Estatística [IBGE], 2014), o Brasil tem reduzido o analfabetismo estando atualmente com um índice de $8,3 \%$ de analfabetos. No entanto, a maioria dessas pessoas se encontra na faixa etária acima de 40 anos, por exemplo, e a taxa de analfabetismo abaixo dos 30 anos é somente de $3 \%$. É importante ressaltar que as mudanças ocorridas pelas condicionalidades do Programa Bolsa Família, como a obrigatoriedade de ida a escola, atuaram de forma importante no aumento da escolaridade no público infanto juvenil.

Outra diferença da área rural está relacionada a uma evidência de maior pobreza multidimensional na dimensão habitação. Talvez isso ocorra porque as mudanças estruturais levam mais tempo para ocorrer no contexto rural, que geralmente é marcado por uma situação de privação estrutural mais forte, como a falta de saneamento básico e eletricidade. De acordo com Albuquerque (2001), as áreas rurais são mais precarizadas estruturalmente à medida que as políticas públicas têm sido desenvolvidas de forma mais efetiva principalmente nos contextos urbanos. Por conta da sua distância dos grandes centros urbanos, a compra de material para a construção de casas com melhor qualidade se torna mais onerosa para os moradores de áreas rurais.

Outra dimensão que não teve diferença significativa foi a da saúde para os moradores da zona urbana e rural. A partir dos resultados dessa dimensão, considera-se que ela seria uma das dimensões que teria um menor índice de privação. O relatório da FAO (2014) revela que houve uma mudança expressiva na redução da fome e da desnutrição no Brasil nos últimos anos, apontando no período de 2012-2014 em seus

Tabela 1. Modelos de Regressão dos Aspectos Subjetivos da Pobreza a Partir das Dimensões da Pobreza Multidimensional nos Contextos Urbano $(n=210)$ e rural $(n=207)$.

\begin{tabular}{|c|c|c|c|c|c|c|}
\hline Tipo de contexto & Passos & Regressores & $\mathbf{R}$ dos modelos & $\mathbf{R}^{2}$ Parciais & $\mathrm{R}^{2}$ ajustado parcial & $\begin{array}{c}\text { Betas } \\
\text { Padronizados }(\beta)\end{array}$ \\
\hline \multirow[t]{4}{*}{ Urbana } & 1 & Dim. Saúde & \multirow{4}{*}{0,516} & 0,152 & 0,148 & $0,265^{* *}$ \\
\hline & 2 & Dim. Habitação & & 0,196 & 0,188 & $0,233^{* *}$ \\
\hline & 3 & Dim. Educação & & 0,238 & 0,227 & $-0,232^{* *}$ \\
\hline & 4 & Dim. Trab/Renda & & 0,266 & 0,252 & $0,185^{*}$ \\
\hline Rural & 1 & Dim. Trab/Renda & 0,232 & 0,054 & 0,049 & $0,232 * *$ \\
\hline
\end{tabular}

${ }^{* *} p<0,01 ;{ }^{*} p<0,05$ 
indicadores, um nível inferior a 5\%, valor abaixo pelo qual se considera que um país superou o problema da fome. A diminuição nos últimos anos dos índices de desnutrição na população brasileira pode ser considerada como outro indicador preditor de uma menor privação na dimensão da saúde em ambos os contextos.

No entanto, não se pode verificar a situação de pobreza somente com essas perspectivas e dimensões baseadas em âmbitos concretos. Dessa maneira, identifica-se que a dimensão subjetiva da pobreza é mais alta nas áreas urbanas que rurais. Os moradores da área rural se sentem menos pobres do que aqueles moradores dos contextos urbanos. No entanto, essa autopercepção da pobreza é mais forte justamente naqueles que têm um menor índice geral de pobreza multidimensional. Portanto, os moradores da zona urbana são menos pobres multidimensionalmente no âmbito geral e concreto, mas se sentem mais pobres quando relacionados aos aspectos subjetivos da pobreza.

De acordo com Wang et al. (2011), pode ocorrer um aumento da percepção de pobreza mesmo quando há uma diminuição da situação de privação do indivíduo. Guardiola, González-Gómez, García-Rubio e LendechyGrajales (2013) confirma essa tendência, como também propõe que esse fenômeno pode ocorrer por conta da comparação social exercida pelo indivíduo. Esses últimos autores salientam que devido às propagandas publicitárias e aos incentivos ao consumo, pode ocorrer a existência de parâmetros elevados e elitistas de comparação social. Dessa maneira, é possível entender a maior percepção de pobreza nos moradores das áreas urbanas por conta dessa influência dos meios de comunicação e por conta da desigualdade social presente na cidade de Fortaleza, que é reconhecida pela Organização das Nações Unidas como uma das cidades mais desiguais do mundo (UN-Habitat, 2013).

Essa mesma perspectiva de entendimento pode ser utilizada para o impacto da desigualdade social na felicidade. Em uma pesquisa survey realizada na Europa e nos Estados Unidos com 123.638 respostas de pessoas sobre felicidade entre as décadas de 70 e 90, foram observadas que ambas as regiões apresentavam menores índices de felicidade quando a desigualdade social é considerada alta, sendo a Europa o local com médias mais elevadas (Alesina, Di Tella, \& Macculloch, 2004). Esse mesmo tipo de investigação ocorreu na América Latina com 18 países a partir de uma amostra de 1.000 entrevistas em cada país no período de 1997 a 2004 de acordo com Graham e Felton (2006). Foi analisado que o bem estar subjetivo era mais baixo nos mais pobres e mais alto nos mais ricos, salientando ainda mais o poder da desigualdade social no território latino americano. É importante salientar que essas investigações ocorreram em contextos urbanos.

Além disso, para entender ainda mais a pobreza a partir de seus aspectos subjetivos, foram realizadas Análises de Regressão Múltipla para avaliar possíveis diferenças nesses aspectos entre zonas rurais e urbanas, tendo sido observado que há resultados contrastantes. Os aspectos subjetivos da pobreza podem influenciar a forma com o indivíduo percebe a sua situação de privação. Dessa maneira, observa-se que a única variável que funciona como preditora positiva da dimensão aspectos subjetivos da pobreza é a dimensão trabalho e renda no contexto rural. Então, quanto mais privado de trabalho e renda, a pessoa se percebe mais pobre subjetivamente. Dessa forma, por mais que a situação da dimensão educação e habitação sejam mais graves na realidade de pobreza rural, as pessoas residentes nessa área somente relacionam a pobreza com aspectos vinculados a trabalho e renda. Isso ocorre, porque pode haver uma adaptação ao contexto de privação desses âmbitos multidimensionais, como afirma Copestake e Camfield (2010).

O pensamento social da pobreza configura-se como um processo sociocognitivo que sustenta os modos de pensar, ser e agir, constituído a partir das relações que se estabelece com o mundo e com os outros e se fazendo presente nas atividades sociais, políticas, econômicas e em todo lugar (Accorssi, 2011). De acordo com a autora, essa forma de pensar que constitui a dimensão subjetiva se aproxima de uma influência da ideologia neoliberal que encara a pobreza somente em uma perspectiva monetária, onde a pobreza é percebida em nível da aquisição ou falta de renda baseada no trabalho.

Igualmente, essa correlação entre aspectos subjetivos e a dimensão trabalho e renda também poderia ser explicada pela concretude do pensamento do morador dos contextos rurais. Pessoas provenientes do contexto rural têm seu desenvolvimento psíquico mais ligado a aspectos concretos da realidade (Ximenes \& Moura Jr., 2013). Assim, pode ser difícil relacionar a situação de pobreza para dimensões que vão além de questões vinculadas ao trabalho e à renda. Diferentemente, os moradores das áreas urbanas vinculam sua percepção da pobreza com as quatro dimensões, entendendo sua situação de maneira mais complexa. 
Então, a dimensão que funciona com maior capacidade preditiva positiva dos aspectos subjetivos é a habitação no contexto urbano. Dessa maneira, quanto mais privado multidimensional na dimensão habitação mais a pessoa do contexto urbano se sente subjetivamente pobre. É importante rememorar que a área rural tem piores condições habitacionais que a área urbana. No entanto, quando a explicação da pobreza ocorre a partir do âmbito subjetivo, pode haver uma inversão da importância de dados concretos e objetivos. Dessa maneira, os moradores da área urbana entendem que a forma como sua casa está constituída é um sinal de pobreza. De acordo com Diener (2012), as pessoas geralmente avaliam suas condições de vida a partir da forma como as outras pessoas próximas vivem. Portanto, como há um relativo livre trânsito de pessoas por diferentes áreas das cidades, as convivências com espaços marcados pela desigualdade social e concentração de riqueza ditam um parâmetro para compreensão de uma realidade de pobreza.

Outra dimensão que também está fortemente relacionada com os aspectos subjetivos da pobreza é a dimensão saúde. Por mais que os contextos urbanos e rurais não tenham diferenças significativas concretas nesse quesito, significando a vivência de uma realidade semelhante na questão da saúde, observamos que os participantes residentes nas áreas urbanas percebem que a privação na dimensão da saúde está ligada a uma percepção de pobreza subjetiva. Isso representa usualmente um pensamento social que o Sistema Único de Saúde (SUS) é um serviço e um sistema para pobre. Assim, os problemas vividos no SUS poderiam ser considerados como representando uma maior situação de pobreza. Quanto a isso, Cotta et al. (2007) nos alertam que apesar de o atendimento no SUS ter caráter universal e irrestrito, o fato desse sistema de saúde ter se originado em um contexto social marcadamente desigual e com restrições orçamentárias na sua implementação, acabou favorecendo uma migração dos grupos sociais. Os setores mais bem remunerados da sociedade, inclusive os profissionais de saúde, passaram a buscar o sistema privado. Tal pressuposto prevalece historicamente na sociedade e fortalece o pensamento de que o SUS é direcionado para a classe pobre.

Apesar de um menor índice de predição, a dimensão escolaridade também se relaciona com a dimensão subjetiva de pobreza no sentido inverso, porque ela funciona como um preditor negativo. Quando há uma maior situação de privação relacionada à educação, há um menor índice de pobreza subjetiva. Isso ocorre porque provavelmente, a educação pode estar ligada a um fortalecimento do senso de criticidade e de expectativas profissionais e pessoais quanto ao futuro. De acordo com Bieńkuńska e Sobestjański (2015), o baixo nível de escolaridade aumenta o risco de permanência na situação de pobreza. Com isso, uma pessoa com baixa escolaridade tende a não identificar mudanças futuras relacionadas à sua melhoria socioeconômica. Conforme Natalino (2014), há uma estratégia de adaptação dos indivíduos pobres não aspirarem melhores condições de vida para não terem a possibilidade de perda de futuras novas aquisições, resguardando-se de possíveis choques proporcionados pela realidade social. Dessa maneira, com uma menor escolaridade, pode-se desejar menos e, assim, se perceber menos pobre que as outras pessoas relembrando que a percepção da pobreza pode estar ligada a uma perspectiva de comparação social.

Por fim, a última dimensão que funciona como uma preditora positiva dos aspectos subjetivos da pobreza é a dimensão trabalho e renda. Apesar do baixo impacto dessa dimensão nesse modelo do contexto urbano, ela igualmente se relaciona positivamente com os aspectos subjetivos da pobreza. A empregabilidade é um dos principais fatores para a saída da situação de pobreza (López-Calva, Lach, \& Fruttero, 2015). Assim, a privação de renda está estritamente vinculada à diminuição das aspirações dos indivíduos (Guardiola et al., 2013). Dessa maneira, com a renda mais baixa em decorrência do desemprego pode-se desenvolver autopercepções de mais pobres. Então, a falta de trabalho e renda aumenta o impacto na sensação de pobreza no indivíduo residente no contexto urbano, sendo esse um ponto já discutido com os moradores de contextos rurais que portam um padrão semelhante.

Identifica-se que o fenômeno da pobreza se constitui de maneira diferente em vários âmbitos no contexto rural e urbano. Primeiramente, é importante salientar que os contextos rurais são geralmente reconhecidos como mais pobres. No entanto, com as análises realizadas em uma perspectiva multidimensional, as diferenças estão somente restritas à educação, habitação e aspectos subjetivos. Dessa maneira, no que se refere a questões monetárias, como trabalho e renda, o contexto rural pesquisado está no mesmo patamar que as comunidades urbanas. Essa mesma tendência ocorre com questões relativas à saúde. Quanto a esta dimensão, 
Campello (2013) reforça que o Programa Bolsa Família (PBF) promoveu a inclusão dos beneficiários na política pública de saúde, fortalecendo a trajetória da saúde de crianças, adolescentes e gestantes em consequência das condicionalidades do programa. Assim, o número de famílias acompanhadas pelo SUS saltou de 5,5 milhões em 2005 para aproximadamente 11,8 milhões em 2012 (Magalhães Jr., Jaime, \& Lima, 2013), cálculo relacionado ao acompanhamento de condicionalidades do PBF. Provavelmente, as ações voltadas à transferência de renda e a ampliação do SUS nos últimos anos podem ter contribuído para o panorama comum entre rural e urbano no quesito da saúde.

Também, é importante ressaltar que a percepção de pobreza está fortemente marcada pela questão do trabalho e renda nos dois contextos. No entanto, no contexto urbano, os aspectos subjetivos da pobreza também estão relacionados com fatores vinculados à educação, à habitação e à saúde. Ou seja, a pobreza é entendida de forma mais complexa e ampliada pelas pessoas que estão neste contexto. Pode-se entender esse resultado devido à desigualdade social mais presente nas grandes cidades. Como as comunidades rurais são geralmente constituídas de forma mais homogênea, não há disparidades extremas como os presentes nas áreas urbanas nas dimensões saúde, educação e habitação.

\section{Considerações finais}

Assim, compreende-se a importância da perspectiva multidimensional para o entendimento da pobreza porque fornece uma visão ampliada e detalhada sobre esse fenômeno. Geralmente, utilizando somente a privação da renda como pobreza, podese perder a perspectiva focalizada de enfrentamento desse fenômeno. Os que residem no contexto rural são mais privados em questões relativas à educação e à habitação. Já os moradores do contexto urbano, são mais privados referentes aos aspectos subjetivos da pobreza, sentindo-se mais pobres que os residentes no contexto rural. Esses últimos somente identificam pobreza como relacionada ao trabalho e à renda diferentemente das pessoas das comunidades urbanas que ligam a pobreza a aspectos vinculados à educação, à saúde, à habitação e ao trabalho e renda.

A partir dos resultados, entende-se que é necessário cada vez mais desenvolver pesquisas e políticas públicas que utilizem a perspectiva multidimensional, como é o caso do Programa Bolsa Família por meio das condicionalidades. No entanto, ainda há uma forte vinculação da multidimensionalidade somente ao padrão de vida, saúde e educação, sendo também importante avaliar a amplitude desse fenômeno complexo a partir da autopercepção da pobreza por parte dos indivíduos e do significado desse fenômeno e da desigualdade social. Tal pressuposto pode contribuir para a discussão de novas formas de enfretamento à pobreza auxiliando ainda mais as políticas públicas no processo de planejamento de suas ações e na oferta de serviços.

Por fim, compreende-se que este estudo ainda carrega consigo algumas limitações, uma vez que na avaliação do aspecto subjetivo da pobreza leva-se em consideração apenas as dimensões da autopercepção de pobreza, vergonha de ser pobre e satisfação com a renda. Contudo, pretende-se avançar cada vez mais com o aprofundamento de outros aspectos relacionados à perspectiva subjetiva da pobreza.

\section{Referências}

Accorssi, A. (2011). Materializações do pensamento social sobre a pobreza. (Tese de doutorado), Recuperado de http://repositorio.pucrs.br/dspace/bitstream/10923/4781/1/000431097-Texto\%2bCompleto-0.pdf

Accorssi, A.; Scarparo, H., \& Guareschi, P. (2012). A naturalização da pobreza: reflexões sobre a formação do pensamento social. Psicologia \& Sociedade, 24(3), 536-546. doi: 10.1590/S0102-71822012000300007

Albuquerque, F. J. B. (2001). Aproximación metodológica desde la psicología social a la investigación en las zonas rurales. Estudios Agrociales y Pesqueros, 19(1), 225-233. Recuperado de http://www. magrama.gob.es/es/ministerio/servicios/publicaciones/art_datos.as p?articuloid $=961 \&$ codrevista $=$ REEAP

Albuquerque, F. J. B. (2002). Psicologia social e formas de vida rural no Brasil. Psicologia: Teoria e Pesquisa, 18(1), 37-42. doi: 10.1590/ S0102-37722002000100005

Alesina, A., Di Tella, R., \& Macculoch, R. (2004). Inequality and happiness: are Europeans and Americans different? Journal of Public Economics, 88, 2009-2042. doi: 10.1016/j.jpubeco.2003.07.006

Avila, R. P., Bagolin, I. P., \& Comin, F. V. (2012). Heterogeneidade individuais versus intensidade da pobreza em Porto Alegre - RS. Revista EconomiA, 13(2), 447-463. Recuperado de http://www.anpec.org. br/revista/vol13/vol13n2p447_463.pdf

Bezerra, R. G. (2009). Usos, apropriações e representações de um espaço urbano. Revista de Ciências Sociais, 4O(1), 43-56. Recuperado de http://www.repositorio.ufc.br/handle/riufc/748

Bieńkuńska, A., \& Sobestjański, K. (2015). Avaliação da pobreza na Polônia. Cadernos de Estudos: Desenvolvimento Social em Debate, 21(1), 180-199. Recuperado de http://docplayer.com. br/5552030-Cadernos-de-estudos-desenvolvimento-social-em-debate.html

Bisquera, R., Sarriera, J. C., \& Martínez, F. (2004). Introdução à estatística: enfoque informático com o pacote estatístico spss. Porto Alegre: ArtMed 
Brasil é segundo país mais desigual do G20, aponta estudo (2012, 19 de janeiro). BBC Brasil. Recuperado de http://www.bbc.co.uk/ portuguese/noticias/2012/01/120118_desigualdade_pesquisa.shtml

Campello, T. (2013). Uma década derrubando mitos e superando expectativas. In T. Campello \& M. C. Neri (Orgs.), Programa Bolsa Família: uma década de inclusão e cidadania. Brasília: IPEA.

Cattani, A. D., \& Ferrarini, A. V. (2010). Participação, desenvolvimento local e política pública: estratégias articuladas para a superação da pobreza. Revista Katál, 13(2), 164-172. doi: 10.1590/S141449802010000200003

Chiappero-Martinetti, E. (2000). A multidimensional assessment of well-being based on Sen's functioning approach. Rivista Internazionale di Scienze Sociali, 2, 207-239. doi: 10.2307/41634742

Copestake, J., \& Camfield,L. (2010). Measuring multidimensional aspiration gaps: a means to Uunderstanding cultural aspects of poverty. Development Policy Review, 28(5), 617-633. doi: 10.1111/j.1467$-7679.2010 .00501 . x$

Cotta, R. M. M.; Gomes, A. P.; Maia, T. M.; Magalhães, K. A.; Marques, E. S., \& Siqueira-Batista, R. (2007). Pobreza, injustiça, e desigualdade social: repensando a formação de profissionais de saúde. Revista brasileira de educação médica, 31(3), 278-286. doi: 10.1590/S010055022007000300010

Diener, E (2012). New findings and future directions for subjective well-being research. American Psychologist, 67(8), 590-597. doi: 10.1037/a0029541

Distante, R. (2013). Subjective well-being, income and relative concerns in the UK. Social Indicators Research, 113(1), 81-105. doi 10.1007/ s11205-012-0083-Z.

Graham, C., \& Felton, A. (2006). Inequality and happiness: insights from Latin America. Journal of Economic Inequality, 4, 107-122. doi: 10.1007/s10888-005-9009-1

Guardiola, J., González-Gómez, J., García-Rubio, M. A., \& Lendechy-Grajales, A. (2013). Does higher income equal higher levels of happiness in every society? The case of the Mayan people. International Journal of Social Welfare, 22, 35-44. doi: 10.1111/j.1468$-2397.2011 .00857 . x$

Instituto Brasileiro de Geografia e Estatística (2014). PNAD 2013 retrata mercado de trabalho e condições de vida no país. Recuperado de http://saladeimprensa.ibge.gov.br/noticias?view=noticia\&id=1\&bu sca $=1$ \&idnoticia $=2722$

Instituto de Pesquisa e Estratégia Econômica do Ceará (2012). Perfil Municipal de Fortaleza. Tema VIII: O Mapa da Extrema Pobreza. (Informe no 43). Fortaleza: IPECE. Recuperado de http://www.ipece. ce.gov.br/publicacoes/ipece-informe/lpece_Informe_43_05_novembro_2012.pdf.

Instituto de Pesquisa e Estratégia Econômica do Ceará (2014a). Caracterizando a redução da extrema pobreza no Ceará: uma análise comparativa com Brasil e Nordeste (Informe no 81). Fortaleza: IPECE.

Instituto de Pesquisa e Estratégia Econômica do Ceará (2014b). Perfil Básico Municipal: Apuiarés. Fortaleza: IPECE. Recuperado de http://www.ipece.ce.gov.br/publicacoes/perfil_basico/pbm-2014/ Apuiares.pdf.

Lelli, S. (2001). Factor analysis vs. Fuzzy sets theory: assessing the influence of different techniques on sen's functioning approach. Discussion Paper Series, Center for Economics Studies. Recuperado de http://econpapers.repec.org/paper/wpepapers/ces0121.htm
López-Calva, L. F.; Lach, S., \& Fruttero, A. (2015). Avaliação da pobreza na Polônia. Cadernos de Estudos: Desenvolvimento Social em Debate, 15(1), 136-154.

Loureiro, A. O. F.; Suliano, D. C., \& Oliveira, J. L. (2010). Uma análise da pobreza no Ceará em diferentes linhas de mensuração (Texto para discussão n. 87). Fortaleza: IPECE. Recuperado de www.ipece. ce.gov.br/publicacoes/textos_discussao/TD_87.pdf.

Magalhães Jr., H. M.; Jaime, P. C., \& Lima, A. M. C. (2013). O papel do setor saúde no programa bolsa família: histórico, resultados e desafios para o sistema único de saúde. In T. Campello \& M. C. Neri (Orgs.), Programa Bolsa Família: uma década de inclusão e cidadania. Fortaleza: IPEA.

Moura Jr., J. F.; Cidade, E. C.; Ximenes, V. M., \& Sarriera, J. C. (2014). Concepções de pobreza: um convite à discussão psicossocial. Temas em Psicologia, 22(2), 341-352. doi: 10.9788/TP2014.2-06

Moura Jr., J. F., Ximenes, V. M., \& Sarriera, J. C. (2014). A construção opressora da pobreza no Brasil e suas consequências no psiquismo. Quaderns de Psicologia, 16(2), 85-93. doi: 10.5565/rev/ qpsicologia.1174

Natalino, M. A. C. (2014). Pesquisa painel de pobreza: aspectos teórico-metodológicos da estratégia brasileira de enfrentamento à pobreza. Revista Brasileira de Monitoramento e Avaliação, 4(1), 124-135.

Organização das Nações Unidas para a Alimentação e a Agricultura (2014). O estado da segurança alimentar e nutricional no Brasil: um retrato multidimensional. Recuperado de https://www.fao.org. br/download/SOFI4_Brasil.pdf.

Picolotto, V. C. (2006). Pobreza e desenvolvimento sob os paradigmas da renda e das capacitações: uma aplicação para a Grande Porto Alegre através dos indicadores fuzzy. (Dissertação de Mestrado). Recuperado de http://hdl.handle.net/10183/10575.

Pinto, A. R., Borges, J. C., Novo, M. P., \& Stoeckli, P. (2014). Apresentação. Cadernos de Estudos: Desenvolvimento Social em Debate, 15(1), 9-182004.

Programa das Nações Unidas para o Desenvolvimento (2010). Relatório de Desenvolvimento Humano. A verdadeira riqueza das nações: vias para o desenvolvimento humano. Recuperado de http://hdr.undp.org/ en/media/HDR_2010_PT_Complete_reprint.pdf.

Programa das Nações Unidas para o Desenvolvimento (2014). Relatório de Desenvolvimento Humano. Sustentar o Progresso Humano: reduzir as vulnerabilidades e reforçar a resiliência. Recuperado de www.pnud.org.br/arquivos/RDH2014pt.pdf

Qizilbash, M., \& Clark, A. (2005). The capability approach and fuzzy poverty measures: an application to the South African context. Social Indicators Research, 74, 103-139. doi: 10.1007/s11205005-6527-y

Samman, E. (2007). Psychological and subjective wellbeing: a proposal for a internationally comparable indicators (Working Paper Series 05). Oxford Poverty \& Human Development Initiative.

Sen, A. (2000). Desenvolvimento como liberdade. São Paulo: Companhia das Letras.

Spicker, P., Leguizamón, S. A., \& Gordon, D. (2009). Pobreza: un glosario internacional. Buenos Aires: Consejo Latinoamericano de Ciencias Sociales - CLACSO.

UN-Habitat. (2013). State of The World's Cities 2012/2013: Prosperity of Cities. Routledge: Nova lorque. Recuperado de http://mirror.unhabitat.org/pmss/listltemDetails.aspx?publicationID=3387 
Ximenes, V. M.; \& Moura Jr., J. F. (2013). Psicologia comunitária e comunidades rurais do Ceará: caminhos, práticas e vivências em extensão universitária. In J. F. Leite \& M. Dimenstein (Orgs.), Psicologia e contextos rurais. (Vol. 1, pp. 453-476). Natal: EDUFRN:

Wang, X., Shang, X., \& Xu, L. (2011). Subjective well-being poverty of the elderly population in china. Social Policy and Administration, 45(6), 714-731. doi: 10.1111/j.1467-9515.2011.00804.x
Werneck, F.; \& Leal, L. N. (2011, 21 de dezembro). Favelas concentram 6\% da população brasileira, com 11 milhões de habitantes. Estadão. Recuperado de http://www.estadao.com.br/noticias/cidades,favelas-concentram-6-da-populacao-brasileira-com-11-mi-de-habitantes,813838,0.html

Zavaleta, D. R. (2007). The ability to go about without shame: a proposal for internationally comparable indicators (Working Paper 03).Oxford Poverty \& Human Development Initiative, OPHI. Recuperado de http://www.ophi.org.uk/working-paper-number-03/

\footnotetext{
${ }^{1}$ Artigo resultante de uma pesquisa financiada pelo Edital MCTI/CNPq/MEC/CAPES N $\cong 07 / 2011$.

${ }^{2}$ Equivalente a $\mathrm{R} \$ 3,25$ aproximadamente no mês de janeiro de 2014.

${ }^{3}$ Embora obtenha como fonte de pesquisa os dados do IBGE e da PNAD, referentes aos anos de 2012 e 2013, o IPECE classifica a população em extrema pobreza aquela com renda domiciliar per capita igual a $R \$ 83,68$, valor em reais de setembro de 2013 , equivalente à linha oficial de $R \$$ 70,00 , definida pelo governo federal para setembro de 2010.

${ }^{4}$ Valor equivalente a um salário mínimo no ano de 2013 , ano em que o questionário foi aplicado.
}

Verônica Morais Ximenes, Doutora em Psicologia pela Universidade de Barcelona (UB), Pós-doutorado em Psicologia pela Universidade

Federal do Rio Grande do Sul (UFRGS), é Professora Associada do Programa de Pós-graduação em Psicologia da Universidade

Federal do Ceará (UFC) e coordenadora do Núcleo de Psicologia Comunitária (NUCOM). Endereço para correspondência: Av. da Universidade, 2762. Benfica. Fortaleza, Ceará 600020-180.

Telefone: (085) 3366 7729. E-mail: vemorais@yahoo.com.br

James Ferreira Moura Júnior, Doutor em Psicologia pela Universidade Federal do Rio Grande do Sul (UFRGS), é Professor Adjunto do Instituto de Humanidades e Letras da Universidade da Integração Internacional da Lusofonia Afro-Brasileira (UNILAB).E-mail: jamesferreirajr@gmail.com

Janaína Miranda Cruz, Mestre em Psicologia pela Universidade Federal do Ceará (UFC), é Psicóloga do Centro de Referência da Assistência Social (CRAS) do Município do Euzébio (Ceará). E-mail: janaina.mcruz@yahoo.com.br

Lorena Brito da Silva, Mestre em Psicologia pela Universidade Federal do Ceará (UFC), é Professora da Faculdade Luciano Feijão (FLF), Sobral (Ceará). E-mail: lorena.nessin@gmail.com

Jorge Castellá Sarriera, Doutor em Psicologia Social pela Universidade Autônoma de Madrid (UAM), Pós-doutorado em Psicologia Comunitária na Universidade de Barcelona e na University of San Francisco (CA-USA), é Professor Associado do Instituto de Psicologia da Universidade Federal do Rio Grande do Sul (UFRGS) e coordenador do Grupo de Pesquisa em Psicologia Comunitária da Universidade Federal do Rio Grande do Sul - GPPC/UFRGS.

E-mail: jorgesarriera@gmail.com

Recebido em 09.Abr.15

Revisado em 15.Mar.16

Aceito em 25.Mai.16 